\title{
Korunan Alan Kaynak Değerlerine İlişkin Ziyaretçi Tercihlerinin Sosyal Medya Verileri Kullanılarak Belirlenmesi
}

\author{
Sevgi Öztürk \\ Kastamonu Üniversitesi \\ Mühendislik ve Mimarlik Fakültesi \\ orcid.org/0000-0002-3383-7822 \\ Sena Ayvadoğlu \\ Kastamonu Üniversitesi \\ Fen Bilimleri Enstitüsü \\ orcid.org/0000-0002-8273-9292 \\ Eren Özben Kütahyalı \\ Kastamonu Üniversitesi \\ Fen Bilimleri Enstitüsü \\ orcid.org/0000-0003-1508-3198
}

\author{
Merve Kalaycı Kadak* \\ Kastamonu Üniversitesi \\ Mühendislik ve Mimarlık Fakültesi \\ orcid.org/0000-0003-1109-050X
}

\author{
Ahmet Saat \\ Kastamonu Üniversitesi \\ Fen Bilimleri Enstitüsü \\ orcid.org/0000-0003-4090-8868 \\ Özge Köleoğlu \\ Kastamonu Üniversitesi \\ Fen Bilimleri Enstitüsü \\ orcid.org/0000-0003-1278-7368
}

\section{$\ddot{O} z$}

Hızla artış gösteren teknolojik gelişmeler, sosyal medya kullanımını da arttırmıştır. Bireyler sosyal medyada fotoğraflar ve videolar paylaşarak, bir alanın tanınırlı̆̆ın arttırabilmektedir. Bu alanlardan bazıları korunan alanlardır. Korunan alanların kaynak değerleri, ziyaretçiler tarafından sosyal medya paylaşımı yapılmasına olanak sağlamaktadır. Çalışma alanı olarak Küre Dă̆ları Milli Parkı (KDMP) seçilmiştir. Sosyal medya uygulaması olan Instagram üzerinden KDMP etiketiyle yapılan paylaşımlar incelenmiş ve sınıflandırılmışıı. Ayrıca katılımcılara sosyal medya üzerinden alana ilişkin bir anket uygulanmış ve anket verileri ki-kare analizine tabi tutulmuştur. Analiz sonuçları ve Instagram'dan elde edilen veriler karşılaştırılarak, birbirlerini doğrulama durumu tespit edilmiştir. Sonuç olarak ise alanın kaynak değerlerinden ön plana çıkanlar/geri planda kalanlar tespit edilmiş ve öneriler geliştirilmişsir.

Anahtar Kelimeler: Korunan Alan, Koruma, Instagram, Sosyal Medya, Ki-kare Testi

\section{Determination of Visitor Preferences for Protected Areas Resource Values Using Social Media Data}

\begin{abstract}
In today's world, the rapid increase in technological developments raised the use of social media. Individuals can increase the recognition of an area by sharing photos and videos on social media. Some of those popular areas are the protected areas. Protected areas resource values enable visitors to share in social media. Kure Mountains National Park (KDMP) is selected as a study area. On social media application Instagram, the shares made with KDMP tag are examined and classified. In addition, a questionnaire about the field is applied to the participants via social media. The questionnaire data are subjected to chi-square analysis. Analysis results and the data obtained from Instagram are compared to determine the verification status of each other. As a result, the prominent / subordinated resource values of area are determined and suggestions are made.
\end{abstract}

Keywords: Protected Area, Conservation, Instagram, Social Media, Chi-Square Test 


\section{Giriş}

Son yıllarda yaşanan teknolojik gelişmeler ile birlikte sosyal medya kullanımı da gün geçtikçe artmaktadır. Günlük hayatta bilgiye erişmek için hızlı çözümler geliştiren sosyal medya uygulamaları, kullanıcılar tarafından sıklıkla tercih edilmektedir. Günümüzde popülerliği hızla artan uygulamalardan biri de Instagram adlı aplikasyondur. Instagram, son yıllarda hızlı yeni bir araç olarak ortaya çıan, mobil fotoğraf yakalama ve paylaşma hizmetidir. Ekim 2010'da piyasaya sürüldüğünden beri 150 milyondan fazla kayıtlı kullanıcı ile Instagram, popüler bir fotoğraf (video) çekme uygulaması haline gelmiştir. Ayrıca, kullanıcıların resimlerini ve videolarını tanımlamak için \# sembolünü kullanarak altyazı eklemelerini ve diğer kullanıcıları etiketlemelerini ya da bunları göndermeden önce @ işaretini (gönderilerinden referans verilen kullanıcının hesabına etkili bir şekilde oluşturarak) etiketlemelerini veya bunlardan bahsetmelerini sağlar (Hu ve ark.,2014). Çoğunlukla kişilerin Instagram hesaplarında paylaşım yapmak için özel bir fon olarak kullanabilecekleri alanları tercih ettikleri gözlemlenmiştir. Estetik ve doğal özellikleri ile ön planda olan, genellikle bünyesinde güzel manzaralar barındıran alanların daha çok tercih edildiği bilinmektedir. Manzara noktalarıyla paylaşım yapmak için tercih edilen bu alanlardan birisi de korunan alanlar olmaktadır.

Korunan alanlar, biyolojik çeşitliliğin, doğal ve kültürel kaynakların korunması için önemli araçlardan biridir (Arpa, 2011; Çetin ve Şevik, 2016). En önemli korunan alan türlerinden biri olan milli parklar, geçmişte yalnızca insan faaliyetlerinin yasaklandığı ya da sınırlandığı alanlar olarak algılanırken; günümüzde özellikle bilimsel değeri yanında estetik değeriyle de koruma altına alınan, sahip oldukları kaynak değerleri ile rekreasyonel kullanımlara olanak tanıyan, toplumun fizyolojik, psikolojik, ekonomik ve sosyal gelişimine katkıda bulunan alanlar olarak görülmektedirler. Bu alanlar; vejetasyon, yaban yaşamı, ilginç jeolojik formasyonları, su öğeleri gibi kaynak değerlerine sahip olması ile insan kullanımlarına da belirli ölçüde izin vermektedir (Öztürk, 2005; Türker ve Öztürk, 2013; Çetin ve Şevik, 2015). Kullanıcılar bu kaynak değerlerini Instagram, Facebook gibi sosyal medya ağlarında paylaşarak alanların tanınırlığını artırmaktadır. Ancak, hassas ekosistemlere sahip bu alanlar ziyaretçiler nedeniyle müdahale görebilmekte ve baskı altında kalmaktadır (Alaeddinoğlu vd., 2013). Bu nedenle sürdürülebilir koruma-kullanma dengesini sağlayabilmek için yönetim stratejilerinin belirlenmesinde insanlar ile yaban yaşamı arasındaki çatışmaların incelenmesi ve değerlendirilmesi gerekmektedir (Masabo, 2013). Çalışmada sosyal medya ağlarında, Küre Dağları Milli Parkı (KDMP) paylaşımları ve yapılan anket çalışması bulguları neticesinde çıkan sonuçların analiz edilerek; alanın kaynak değerlerine ilişkin öneriler geliştirilmiştir.

\section{Materyal ve Yöntem}

KDMP, Karadeniz Bölgesi'nin Batı Karadeniz bölümünde Küre Dağları üzerinde, Kastamonu ve Bartın il sınırları içerisinde yer alır. 37.753 ha büyüklüğünde olup, çevresinde 134,366 ha alan tampon bölge olarak ayrılmıştır. Türkiye' de tampon bölge kavramı ilk kez bu alan için kullanılmıştır. Alanın toplam büyüklüğü 172.119 
ha'dır. Milli parkın bulunduğu bölge içinde hiçbir yerleşim birimi bulunmamakta, sosyal hayat milli parkın yakın çevresinde devam etmektedir. Milli Park tampon sınırında 8 ilçe, 123 köy bulunmaktadır (Şekil 1) (URL-1). Yakın çevresi için fiziksel ve sosyal anlamda bir eşik niteliğindedir.

Doğal, kültürel ve estetik kaynak değerleri açısından oldukça zengin olan alan, 07.07.2000 tarihinde Türkiye'nin katılımcı bir anlayışla sınırları çizilen ilk milli parkı olarak ilan edilmiştir (Öztürk, 2005, Öztürk vd.,2018). KDMP günümüzde tehlike altındaki "Karadeniz Nemli Karstik Orman" ekosistemlerinin en iyi yabanıl örneklerine sahip ve Avrupa' da korunması gereken 100, Türkiye'de ise 9 Orman Sıcak Noktası içinde yer almaktadır (Görmüş ve ark., 2015). Milli park taşıdığı ekosistem, fauna ve flora özellikleri dolayısıyla 2000 yılında "Milli Park" statüsü, 2012 yılında ise PAN Parks sertifikası alarak Türkiye'nin ilk, Dünya'nın ise 13. PAN Parks sertifikalı alanı olmuştur (Atmış, 2009; Şen ve Güngör, 2018). Kanyonlar ve mağaralar açısından Türkiye'nin en zengin noktalarından biri olarak kabul edilen Milli Park aynı zamanda Toros Dağları'ndan sonra Türkiye'nin en önemli ikinci karstik alanıdır (Akbulut ve ark., 2015).

KDMP, Uzun Devreli Gelişim Planı Haritasında yer alan planlama kararlarına göre; mutlak koruma bölgesi, hassas koruma (yabanıl) bölgesi, sürdürülebilir kullanım bölgesi, kontrollü kullanım bölgesi ve tampon bölge olarak 5 sınıfa ayrılmıştır (URL-2).

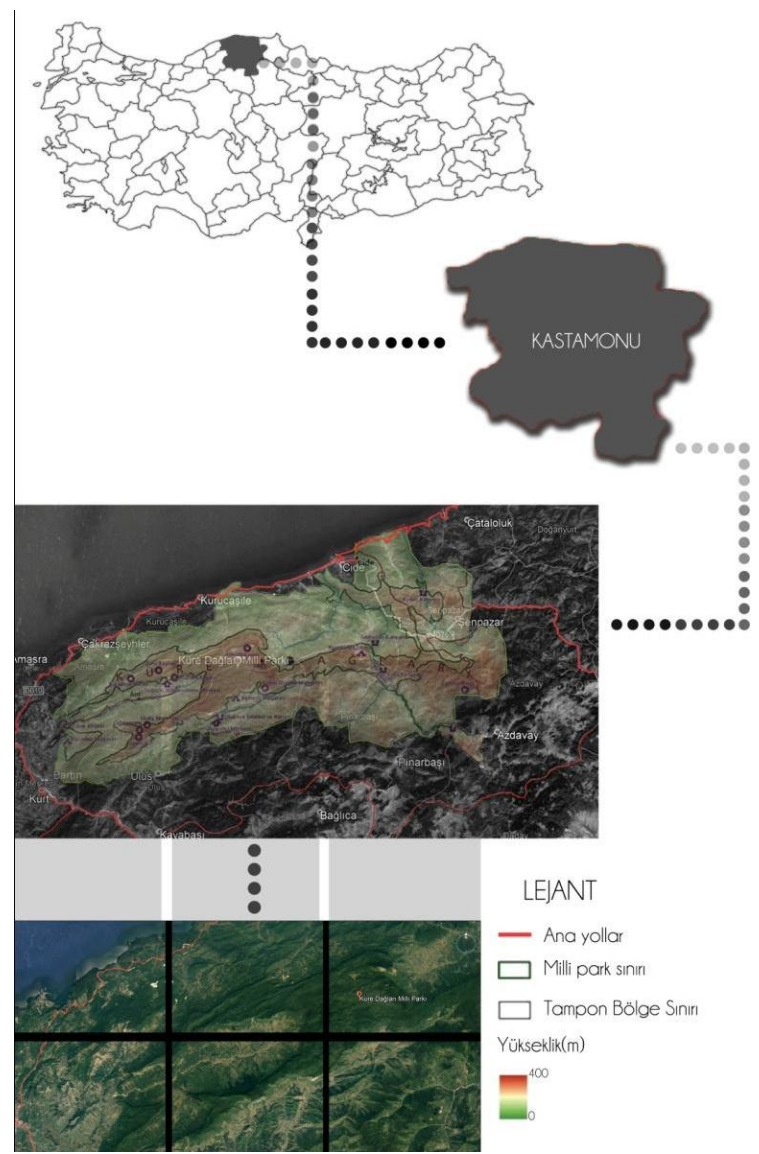

Şekil 1. KDMP sınırları 
Çalışma 3 aşamalı olarak gerçekleştirilmiştir (Şekil 2). Birinci aşamada; ulusal ve uluslararası literatür araştırması yapılarak alan hakkında bilgilere ulaşılmıştır. İkinci aşamada; çalışmanın temelini oluşturan sosyal medya analizi için, Instagram uygulamasından son iki yılda paylaşılan fotoğraf ve videolar taranmıştır. Üçüncü aşamada Google form eklentisi ile sosyal medya kullanıcılarına yönelik olarak, KDMP'na ilişkin bir anket hazırlanmıştır.

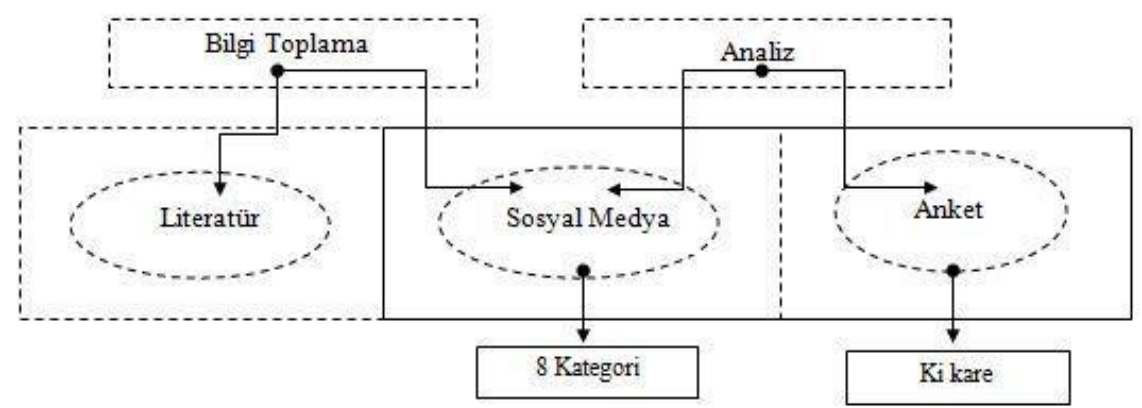

Şekil 2. Çalışma yöntemi

Daha sonra yapılan paylaşımlar; manzara, hayvanlar, bitkiler, yiyecek, doğa sporları, su ögeleri, kişi pozu, mimari yapı olmak üzere 8 kategoriye ayrılmış ve taranan fotoğrafların kategoriler bazında yoğunluğu hesaplanmıştır (Tablo 1).

Tablo 1. Fotoğraf Kategorileri ve Tanımları (Hausman ve ark., 2017' ndan geliştirilmiştir)

\begin{tabular}{ll}
\hline \multicolumn{1}{c}{ Kategori adı } & \multicolumn{1}{c}{ Kategori tanımı } \\
\hline Manzara & KDMP' nın manzara alanlarını içeren fotoğraflar \\
Hayvanlar & Alandaki yaban hayatına ilişkin fotoğraflar \\
Bitkiler & Bitki örtüsüne ilişkin fotoğraflar \\
Yiyecek & Yöresel ya da alana özel yiyecek fotoğrafları \\
Doğa Sporları & Kış sporları, trekking gibi alanın izin verdiği spor çeşitlerine \\
Su Öğeleri & ilişkin fotoğraflar \\
Kişisel Poz & Milli Park'ın kaynak değerlerinden suya ilişkin fotoğraflar \\
Mimari & Ziyaretçilerin ya da yakınlarının fotoğrafları \\
\hline
\end{tabular}

Anket, sosyal medya platformları üzerinden paylaşılarak 102 ayrı Facebook, Twitter ve Instagram kullanıcısı tarafından yanıtlanmıştır. Katılımcılara, KDMP ve yaptıkları paylaşım tercihleri hakkında toplam 16 soru sorulmuş olup, bunlardan ilk üçü, katılımcıların demografik yapısına ilişkin sorulardır. Evet/hayır seçenekleri ile ilerleyen sorularda paylaşım yapmak istedikleri kategoriler sorgulanmıştır. Anket çalışması sonucunda elde edilen verilerin, birbirleriyle ilişkisini ortaya koymak amacıyla; verilere SPSS 20.00 paket programı ile kikare istatistiki analizi uygulanmıştır. Çıkan analiz sonuçlarının, Instagram tarama sonuçları ile karşılıklı durumları tespit edilerek verilerin yorumlamaları gerçekleştirilmiştir. 


\section{Bulgular}

Çalışmada, sosyal medya verilerinin sayısal ve oransal durumunun ortaya koyulması için anket verileri ve Instagram uygulamasında yapılan veri taramasının kullanılması uygun görülmüştür. Günümüzde Instagram uygulamasının fotoğraf paylaşımındaki artan popülerliği, medya paylaşımı ve kullanıcılara kolay erişebilirliği sebebiyle önemli bir veri kaynağı olduğu düşünülmektedir. KDMP için yapılan çalışmada, son iki yıl içerisinde aktif kullanıcılar tarafından paylaşılan "\#küredağları" etiketi ile paylaşılmış fotoğraf ve videolar taranmış, 982 adet fotoğraf ve 152 adet video ile toplamda 1.134 adet sosyal medya paylaşımına ulaşılmıştır. Fotoğraflarda ana konulara dayalı bir sınıflandırma yaklaşımı benimsenmiş (Richards \& Friess, 2015); manzara, hayvanlar, bitki, yiyecek, doğa sporları, su öğeleri, kişi pozu ve mimari yapı olmak üzere 8 kategoriye ayrılmış ve fotoğraf sayımı bu sınıflandırmaya göre gerçekleştirilmiştir. Instagram uygulamasında kategorilere göre paylaşımlar şöyledir (Şekil 3): Manzara için 375, kişisel poz için 266, su öğesi için 117, mimari öğeler için 61, bitkiler için 60, doğa sporları için 56, hayvanlar için 34, yöresel yiyecek içecek için 13, fotoğraf paylaşıldığı ve ayrıca 152 video paylaşıldığı tespit edilmiştir.

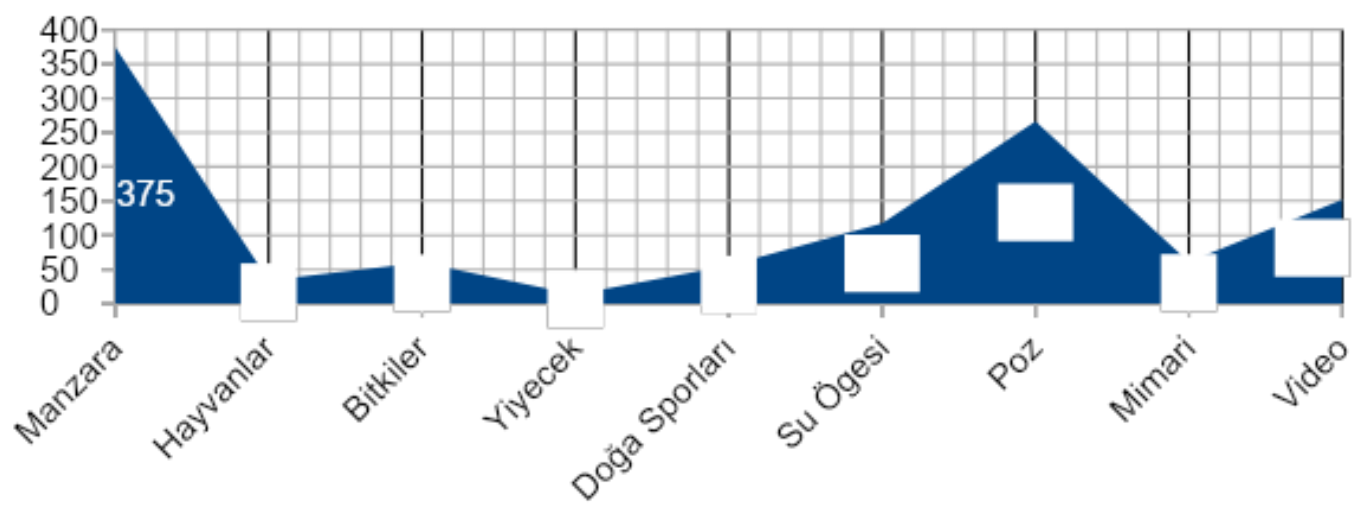

Şekil 3. Instagramda \#küredağları Etiketi İle Paylaşılmış Fotoğrafların Dağılımı (20172018).

Ayrıca çalışmada Instagram uygulamasından elde edilen sınıflandırma sonuçlarının ötesinde Google form eklentisi ile anket formu oluşturulmuştur. Bu şekilde, KDMP özelinde paylaşım tercihleri üzerine kurgulanan anket çalışması ile katılımcıların alanı ziyaret ederken deneyimledikleri yada deneyimlemek istedikleri kategorilerin belirlenmesi bağlamında Instagram uygulaması verileri ile örtüşüp örtüşmedikleri tespit edilmesi amaçlanmıştır. Böylece; KDMP için cazibe kaynak değerlerinin belirlenebileceği öngörülmektedir.

102 katılımcının \%57,8'i kadınlardan, \%42,2'si erkeklerden oluşmaktadır. Bu kişilerin \%76,5'i 18-35 yaş aralığında, \%18,6'sı 36-50 yaş aralığında, \%4,9'u ise 50 yaş üstündedir. Katılımcılar eğitim durumlarına göre; \%6,9 ilköğretim, \%6,9 lise, \%63,7 üniversite, \%22,5 lisansüstü olarak ayrılmaktadır. Anketin hedef kitlesinin tamamı sosyal medya kullanıcısı olan kişilerdir. Bu bağlamda katılımcıların \% 67,9' u 
Instagram, \% 19,6' sı Facebook, \% 12,7' si ise Twitter kullanıcısı olarak belirlenmiştir (Şekil 4).
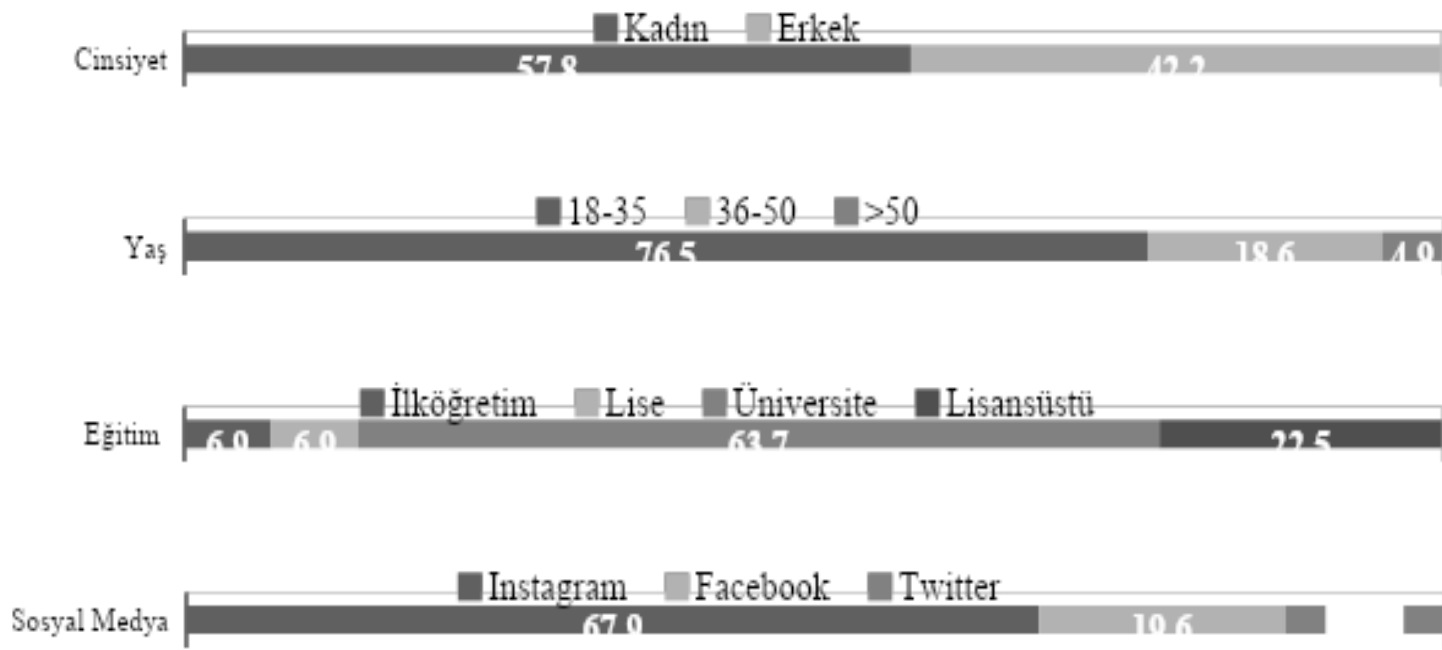

Şekil 4. Anket Katılımcilarının Demografik Yapısı

Kategorilere göre fotoğraf paylaşım durumunun sorgulandı̆̆ soruda; kadınların \%19'u, erkeklerin ise \%42'si manzarayı tercih ederek, manzara kategorisini birinci sıraya taşımışlardır. İkinci sırada ise, kadınlar tarafından doğa sporları tercih edilirken, erkekler tarafından kişi pozu seçeneği tercih edilmiştir. Paylaşım için en az tercih edilen seçenek ise; yaban hayatı ve su öğeleri olmuştur. Yöresel yemekler ise hiç tercih edilmemiştir.

Yaş grupları arasındaki karşılaştırmada ise, katılımcıların 36-50 yaş aralığında \%39'u; 18-35 yaş aralığında ise \%28'i manzara fotoğrafı paylaştıklarını belirtmişlerdir.

Eğitim durumuna göre en yüksek oranda tercih edilen seçenek yine manzara fotoğrafları olmuştur. İkinci sırada doğa sporları tercih edilmiştir. Eğitim seviyesi yükseldikçe, manzara dışındaki su öğeleri, doğa sporları, mimari yapı gibi tercihlere de eğilim görülmektedir. Genel eğilimin tespit edildiği bu kısımdan sonra, ki-kare $\left(\mathrm{X}^{2}\right)$ testine tabi tutulan veriler arasında istatistiksel açıdan ilişki bulunup bulunmadığını belirlemeye yarayan P (Asymp. Sig.) değerleri (Uzgören ve Uzgören, 2007; URL-3; Kalaycı ve Öztürk, 2018) incelenmiş ve aşağıdaki durumlar tespit edilmiştir.

Katılımcıların KDMP'nda fotoğraf çekme durumlarının sorgulandığı soruda; cinsiyet, eğitim durumu ve kullanılan sosyal medya çeşidine göre istatistiki olarak ilişki olduğu tespit edilmiştir (Tablo 2). 
Tablo 2. Fotoğraf çekmeye ilişkin istatistiki ilişki durumu

\begin{tabular}{lll}
\hline & $\mathbf{X}^{2}$ & $\mathbf{P}^{*}$ \\
\hline Cinsiyet & 7,708 & 0,005 \\
Eğitim & 15,853 & 0,001 \\
Sosyal Medya & 6,305 & 0,043 \\
\hline$\times P<0,05$ & &
\end{tabular}

Kadınların \%37,3' ü, erkeklerin \%65,1' i evet seçeneğini tercih ederek 0,005 anlam düzeyinde bir ilişki ortaya koymuştur. Eğitim durumu ilköğretim olanlardan $\% 14,3^{\prime}$ ü, lise olanlardan $\% 28,6$ ' sı, üniversite olanlardan $\% 43,1^{\prime}$ i, lisansüstü olanlardan $\% 82,6$ ' s1 evet seçeneğini tercih etmiştir ve 0,001 anlam düzeyinde ilişki ortaya koymuştur. Sosyal medya kullanım tercihlerine göre; Instagram kullananlardan \%40,6' s1, Facebook kullananlardan \%70' i, Twitter kullananlardan \%61,5' i evet seçeneğini işaretleyerek 0,043 anlam düzeyinde bir ilişki ortaya koymuştur (Şekil 5).

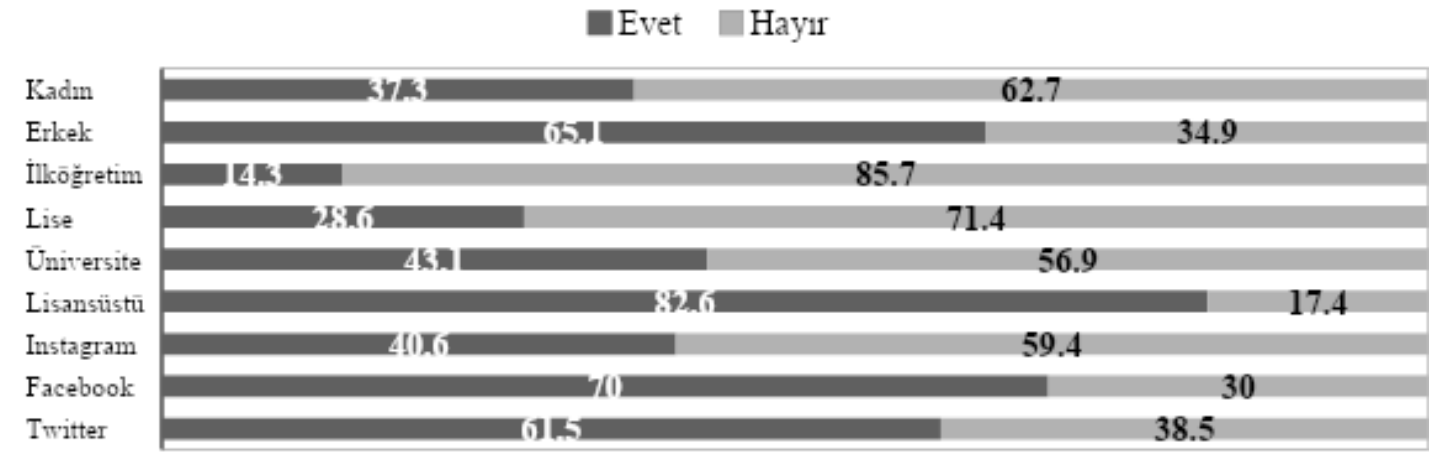

Şekil 5. Katılımcıların KDMP'nda Fotoğraf Çekme Durumları

Katılımcıların KDMP'nda fotoğraf çekmeleri ve paylaşmalarına yönelik soruların bazılarında anlamlı farklılıklar ortaya koydukları gözlenmiştir (Tablo 3).

Tablo 3. KDMP için istatistiki olarak ilişki bulunan veriler

\begin{tabular}{|c|c|c|}
\hline Anket Sorusu & $\begin{array}{c}\text { İlişki } \\
\text { Bulunan Kategori }\end{array}$ & $\mathbf{P}^{*}$ \\
\hline $\begin{array}{l}\text { KDMP'nda sosyal medya hesaplarınızda } \\
\text { paylaşımınız oldu mu? }\end{array}$ & Cinsiyet & 0,01 \\
\hline $\begin{array}{l}\text { KDMP, manzara fotoğrafları çekilmesi açısından } \\
\text { uygun mudur? }\end{array}$ & Eğitim Durumu & 0,01 \\
\hline $\begin{array}{l}\text { KDMP'nda mevsim geçişlerini gösteren } \\
\text { manzara fotoğrafları çeker misiniz? }\end{array}$ & Yaş Grubu & 0,02 \\
\hline
\end{tabular}

${ }^{*} \mathrm{P}<0,05$ 
Katılımcların sosyal medya hesaplarında KDMP fotoğrafları paylaşma durumunun sorgulandığı soruda; kadınların \%30,5' i paylaşım yaptıklarını ifade ederken, erkeklerin \%55,8' i paylaşım yaptığını ifade etmiştir. Cinsiyete göre sosyal medya paylaşımı yapmış olanlar arasında 0,01 anlam düzeyinde ilişki olduğu tespit edilmiştir. Fotoğraf paylaşımı yapmış olmak için, alan ziyareti şart değildir. Bu soru kapsamında kendi çektiğiniz fotoğraf gibi bir kısıtlama özellikle yapılmamıştır. Çünkü KDMP sosyal medya üzerinden çeşitli kişi, kurum ve kuruluş tarafından da bahsedilen bir yerdir.

Katılımcıların KDMP'nı manzara fotoğrafı çekmek açısından uygun bulma durumlarının sorgulandığı soruda; yalnızca eğitim durumuna göre istatistiki olarak 0,01 anlam düzeyinde ilişki olduğu tespit edilmiştir. İlköğretim mezunu olanların $\% 65,7^{\prime}$ si, lise mezunu olanların \%71,4' ü, üniversite mezunu olanların \%96,9' s1, lisansüstü mezunu olanların \%100'ü KDMP'nın manzara değerinin olduğunu düşünmektedir.

Katılımcıların KDMP'nda mevsim geçişlerinin fotoğraflanmasına ilişkin durumlarının sorgulandığı soruda; yalnızca yaş grubuna göre istatistiki olarak 0,02 anlam düzeyinde ilişki olduğu tespit edilmiştir. 18-35 yaş grubundaki katılımcıların $\% 82,1$ ' i, 36-50 yaş grubundaki katılımcıların \%52,6' s1, 50 yaş ve üstü grubundaki katılımcların ise \%40' 1 KDMP'nın mevsim geçişlerini yansıtan manzarasının fotoğrafını çekmek isteyeceğini belirtmiştir.

Ankette katılımcılara yöneltilen diğer sorularda istatistiki olarak ilişki bulunamamıştır. Bu sorular ve $\mathrm{P}$ değerlerinin olduğu tablo aşağıda verilmiştir (Tablo $4)$.

Tablo 4. KDMP İçin İstatistiki İlişki Bulunmayan Veriler

\begin{tabular}{|c|c|c|c|c|c|c|c|}
\hline & 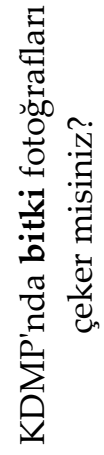 & 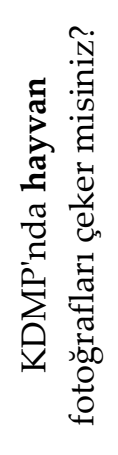 & 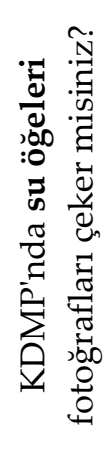 & 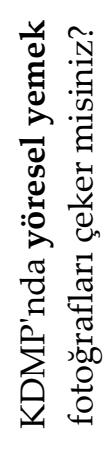 & 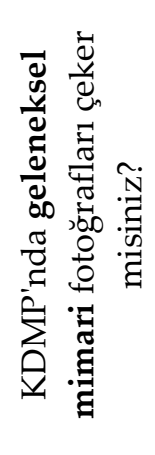 & 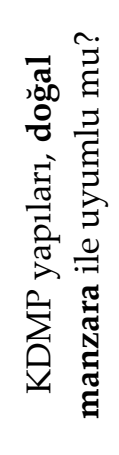 & 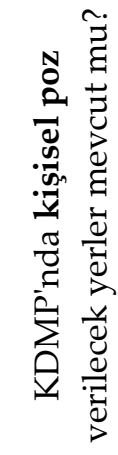 \\
\hline & $\mathrm{P}^{*}$ & $\mathrm{P}^{*}$ & $\mathrm{P}^{*}$ & $\mathrm{P}^{*}$ & $\mathrm{P}^{*}$ & $\mathrm{P}^{*}$ & $\mathrm{P}^{*}$ \\
\hline Cinsiyet & 0,92 & 0,183 & 0,317 & 0,18 & 0,53 & 0,757 & 0,374 \\
\hline Yaş & 0,154 & 0,083 & 0,317 & 0,221 & 0,371 & 0,966 & 0,65 \\
\hline Eğitim & 0,238 & 0,182 & 0,489 & 0,196 & 0,136 & 0,56 & 0,733 \\
\hline Sosyal Medya & 0,675 & 0,848 & 0,361 & 0,785 & 0,173 & 0,787 & 0,264 \\
\hline
\end{tabular}

${ }^{*} \mathrm{P}<0,05$ 
KDMP için yapılan bu ankette yukarıdaki tabloda yer alan sorular için istatistiki olarak bağımlılık bulunamamıştır.

\section{Sonuç ve Öneriler}

Instagram uygulaması üzerinden yapılan taramada, 982 adet fotoğraf ve 152 adet video ile toplamda 1.134 adet sosyal medya paylaşımına ulaşılmıştır. Paylaşımlar çalışma kapsamında belirlenen kategorilere göre değerlendirildiğinde; manzara ve kişisel poz kategorileri açık ara önde tercih edilmiştir. Yöresel yemekler kategorisi sadece 13 katılımcı tarafından tercih edilerek en az tercih edilen paylaşım kategorisi olmuştur.

Anket verileri analiz edildiğinde çıkan sonuçlar, Instagram verilerini kısmen destekler niteliktedir. Manzara seçeneği yapılan anketlerde de daha fazla tercih edilmiş, yöresel yemek seçeneği ise hiç tercih edilmeyerek, Instagram verileriyle paralellik sergilemiştir. Ayrıca eğitim durumuna göre manzara sorgulandığında; eğitim durumu ile doğal manzara farkındalığının doğru orantılı olduğu sonucuna ulaşılmıştır. Eğitim seviyesi yükseldikçe manzara tercihiyle birlikte doğa sporları kategorisi de daha fazla tercih edilir duruma gelmiştir. Ayrıca katılımcıların fotoğraf çekme merakının sorgulandığı soruda; eğitim durumu ile KDMP'nda fotoğraf çekme durumu arasında doğrusal bir orantı olduğu sonucuna ulaşılmıştır.

Demografik verilerden cinsiyete göre kıyaslama yapıldığında; erkek katılımcıların KDMP'nda daha fazla fotoğraf çektiği sonucuna ulaşılmıştır. Bu durum milli parkın ziyaretçilerinin daha çok erkekler olduğu sonucunu da işaret etmektedir.

Yaş kategorilerine göre manzara farkındalığı sorgulandığında; yaş ile manzara farkındalığı arasında ters orantı olduğu tespit edilmiştir. Bu da daha yüksek tahsilli olan katılımcıların genellikle genç yaştaki bireyler olmasının getirdiği bir durum olduğu düşünülmektedir.

KDMP'nda bitki, hayvan, su öğeleri, yöresel yemek, geleneksel mimari öğeler, doğal manzara ile olan uyum ve kişisel poz çekme tercihlerinin sorgulandığı sorularda; hiçbir demografik veriye göre istatistiki olarak ilişki bulunamamıştır. Çünkü bitki ve hayvan varlığı, doğal manzara, geleneksel mimari öğeler ve su öğeleri milli parkın kaynak değerlerinin büyük bir kısmını oluşturmaktadır. Kullanıcılar bu kaynak değerlerini görmek ve bu alanları deneyimlemek için milli park ziyareti yapmaktadırlar. Dolayısıyla herhangi bir kritere (cinsiyet, yaş, eğitim) göre değissiiklik göstermesi beklenmemektedir.

KDMP'nın en önemli kaynak değerlerinden biri olan yaban hayatının çok da tercih edilmemesinin nedeninin, ziyaretçilerin hayvanlarla bir arada bulunabilecekleri imkanların/aktivitelerin bulunmaması olduğu düşünülmektedir. Bazı yurtdışı örneklerde olduğu gibi yaban hayvanlarının beslenme noktaları ve saatleri belirlenerek, ziyaretçilere uzaktan gözlem yapma imkanı sunulabileceği düşünülmektedir. Ayrıca KDMP sınırları içerisinde yer alan bazı noktalarda sunulan yöresel lezzetlerin paylaşım için tercih edilmiyor olmasının nedeninin; lezzetlerin sunumları ve tanıtımları konusunda bazı eksikliklerin bulunması olduğu 
düşünülmektedir. Bu bağlamda yaban hayatı ve yöresel lezzetler için geliştirilecek bazı basit çözümlemeler vasıtasıyla, alan tanınırlığına katkıda bulunulması önerilmektedir.

\section{Kaynakça}

Akbulut, G., Atmış, E., Günşen, H. B. (2015). Farklı İlgi Guruplarının Milli Park Algıları Üzerine Bir Değerlendirme: Küre Dağları Milli Parkı Örneği. Kastamonu Üniversitesi Orman Fakültesi Dergisi, 15(1):133-145.

Alaeddinoğlu, F., Türker, N., Can, A.S., Öztürk, S. (2013). Basic Characteristics, Motivations, and Activities of Ecotourists: A Case Of Lake Van Basin Area, Turkey, The Journal of Academic Social Science Studies, Volume 6 Issue 3, p. 91-107.

Atmış, E. (2009). "PAN Parks" Sürecindeki Küredağları Milli Parkı İçin Bir Örnek: Majella Milli Parkı. Orman Av Dergisi, 4 (2009):8-14.

Çetin, M., Şevik, H. (2016). Evaluating the recreation potential of Ilgaz Mountain National Park in Turkey. Environ Monit Assess 188: 52. https://doi.org/10.1007/s10661-015-5064-7

Çetin, M., Şevik, H. (2016). Assessing Potential Areas of Ecotourism through a Case Study in Ilgaz Mountain National Park. Tourism - From Empirical Research Towards Practical Application 82-110. https://doi.org/10.5772/62573.

Görmüş, S., Atmış, E., Artar, M., Özkazanç, N. K., Günşen, H. B. (2015). Küre Dağları Milli Parkı Köy Tasarım Rehberleri (Bartın Bölümü). Orman Fakültesi Yayınları: 10, 234 s. ISBN: 978- 605-9895-05-07

Hausman, A., Toivonen, T., Slotow, R., Tenkanen, H., Moilanen, A., Heikinheimo, V., Di Minin, E. (2017). Social Media Data Can Be Used to Understand Tourists' Preferences for Nature-Based Experiences in Protected Areas. A journal of the Society for Conservation Biology. Volume11, Issue1. https://doi.org/10.1111/conl.12343

Hu, Y., Manikonda, L., Kambhampati, S. (2014). What we instagram: A first analysis of instagram photo content and user types. Proceedings of the Eighth International AAAI Conference on Weblogs and Social Media, 595-598.

Kalayc1, M., Öztürk, S. (2018). Recreational Activity Habits of Undergraduate Students and Factors Affecting Their Habits: The Case of Kastamonu Univesity Landscape Architecture Department Students. Recent Researches on Social Sciences. 231-241. Krakow.

Masabo, J. (2013). Evaluatıng Effectıveness Of Mitıgatıon Measures Forconflıct Resolution Between Humans And Protected Areas, Case study; Maktau Area in Taita Taveta Region, Kenya. Ankara University Graduate School Of Natural And Applied Sciences, Yüksek Lisans Tezi, Department Of Landscape Architecture, Ankara.

Öztürk, S., (2005). Kastamonu-Bartın Küre Dağları Milli Parkı'nın Rekreasyonel Kaynak Değerlerinin İrdelenmesi. Süleyman Demirel üniversitesi Orman Fakültesi Dergisi, 2, 138-148.

Öztürk, S., Işınkaralar, Ö., Kalaycı, M. (2018). Classification and Ranking of Ecotoruism Resources of Küre Mountains National Park. International Journal of Trend in Research and Development, Volume:5(2), 181-183. 
Türker, N., Öztürk, S., (2013). Perceptions of Residents Towards The Impacts of Tourism in the Küre Mountains National Park, Turkey, International Journal of Business and Social Science, Vol. 4 No. 2.

Richards, D.R. \& Friess, D.A. (2015). A rapid indicator of cultural ecosystem service usage at a fine spatial scale: content analysis of social media photographs. Ecol. Indic.,53, 187-195.

Şen, G., Arıcak, B. (2018). Analysis of Land Use/Land Cover Changes Following Population Movements and Agricultural Activities: A Case Study in Northern Turkey. Applied Ecology and Environmental Research 16(2):2073-2088. http://dx.doi.org/10.15666/aeer/1602_20732088

URL-1. Erişim adresi: http://www.kdmp.gov.tr/sayfa/kure-daglari-milli-parki Erişim tarihi: 4.12.2018.

URL-2. Erişim adresi: https://www.kdmp.gov.tr/kdmp-hakkinda/kdmp-udgp-haritasi Erişim tarihi: 22.2.2019.

URL-3. Erişim adresi: http://www.ekonomianaliz.com/p/ Erişim tarihi: 13.2.2019.

Uzgören, N., Uzgören, E. Dumlupınar Üniversitesi lisans öğrencilerinin memnuniyetini etkileyen bireysel özelliklerin istatistiksel analizi - hipotez testi, ki-kare testi ve doğrusal olasılık modeli. Dumlupınar Üniversitesi Sosyal Bilimler Dergisi, Sayı:17 S:173-192.

Yenilmez Arpa, N. (2011). Türkiye'de korunan alanların belirlenmesi, planlanması ve yönetimi sürecinde katılımclığın değerlendirilmesi: Sultan Sazlığı Milli Parkı. Ankara Üniversitesi Fen Bilimleri Enstitüsü Peyzaj Mimarlığı Anabilim Dalı, Doktora Tezi. Ankara. 